rencias del IPC, o incluso en intervenir en algunos de los proyectos relacionados con los bienes culturales, mientras que los Sitios de interés proporcionan enlaces a través de Internet a múltiples instituciones, fundamentalmente de ámbito nacional aunque también hay una sección dedicada a organismos internacionales, relacionadas con el Patrimonio Histórico y Cultural.

María Victoria Madrid Díaz Centro de Documentación, IAPH

\begin{tabular}{ll}
\hline FICHA DE LA WEB & \\
\hline URL PRINCIPAL & http://www.ipc.gov.ve/ \\
\hline TITULAR & Página elaborada por el Instituto de Patrimonio Cultural de Venezuela \\
\hline INFORMACIÓN DISPONIBLE & Buena (variada y útil) \\
\hline CALIDAD BASES DE DATOS & Media \\
\hline CALIDAD GRÁFICA & Media \\
\hline DISEÑO WEB & Medio \\
\hline FACILIDAD DE NAVEGACIÓN & Buena \\
\hline VELOCIDAD DE CARGA & Rápida \\
\hline ACTUALIZACIÓN & Buena
\end{tabular}

\title{
Castillos en Internet
}

E territorio andaluz cuenta en su haber con innumerables joyas inmobiliarias de gran interés histórico y cultural. De entre ellas, analizaremos en esta ocasión el lugar emblemático que en nuestra geografía ocupan los castillos y fortalezas defensivas. En Andalucía, tenemos en torno a 369 castillos y edificios defensivos declarados BIC (Bien de Interés Cultural), lo que nos hace reflexionar sobre el papel que estos edificios han jugado en la configuración del territorio y en el devenir de la historia de la región.

Todo ello, sin embargo, no se encuentra reflejado del mismo modo en Internet, encontrándose escasos ejemplos de sitios web que muestren de un modo profundo y detallado la historia de estos monumentos, de su emplazamiento, características constructivas, etc. Existen muchas reseñas breves, normalmente acompañadas de algunas imágenes, en sitios dedicados a promocionar el turismo de una determinada comarca, pueblo o ciudad. Como ejemplo, tenemos las referencias que sobre el Alcázar de los Reyes Cristianos de Córdoba podemos encontrar en:

http://www.uco.es/cordoba/.../flores.html, o en http://www.cyberspain.com/ciudades-patrimonio/fotos/coralc.htm

Por otro lado, también podemos encontrar sedes web monográficas que, sin embargo, muestran una información muy somera del edificio, como en el caso del Castillo de La Calahorra en La Calahorra (Granada), que cuenta con un breve recorrido por su estilo y singularidad constructiva, descripción de los elementos arquitectónicos externos, análisis del palacio interior, así como unos mapas de situación dentro de la geografía andaluza y de comunicación por carretera, todo ello acom- pañado de algunas imágenes en un total de seis páginas.

http://www.guadixymarquesado.org/castillo/ent rada.htm

En esta línea contamos también con la página web de la Torre de La Calahorra de Córdoba, hoy por hoy museo de esa ciudad, cuyo contenido nos habla de los espacios museísticos que se muestran en su interior, dedicados a aspectos destacados de la época de Al Andalus con apartados como: Acogida, Los filósofos, Ciencias y técnicas, El Apogeo, La Alhambra, Música, Mezquita, Viaje y Multivisión; aspectos que nos hablan de la época de mayor esplendor en los siglos XII y XIII en un total de once páginas y con algunas imágenes referenciales.

http://www.torrecalahorra.com/index_es.htm

Pero no todo lo que podemos encontrar en Internet sobre este tema está tratado de la misma manera, y por ello, después de estas referencias nos centramos a continuación en un ejemplo de análisis pormenorizado de un castillo en la web, donde a lo largo de 26 páginas podemos realizar un recorrido por sus aspectos constructivos, la situación geográfica, los planos, la historia, así como por los elementos socioculturales y antropológicos de una época -y por el entorno cultural y natural que lo rodea.

Este es el caso de la página web dedicada al Castillo de los Guzmán en Niebla, situado en la provincia de Huelva. Su página principal nos muestra un escudo de armas con la denominación del castillo en el centro, todo con una tipografía y tratamiento claramente medievales (efecto de pergamino en el fondo y letra tipo gótica o similar). En la parte inferior de la pági- na aparecen cuatro apartados que funcionan como entradas principales a la información interior que son: El Castillo, Niebla, Visita Virtual y Turismo. Situándonos con el ratón sobre cada uno de ellos, se despliega un submenú en forma de pergamino con todos los apartados que podemos encontrar en su interior relacionados con estos temas.

Para completar las posibilidades de acceso dentro de la página principal, en los extremos superiores izquierdo y derecho de la misma tenemos dos escudos que actúan también como entradas: uno hacia un bando informativo sobre los eventos estivales del castillo, y otro, hacia una tienda on-line.

Comenzando el recorrido por El Castillo, encontramos los siguientes apartados, de cuyo contenido pasamos a dar algunas pautas:

¿Qué es un castillo?, nos habla de sus orígenes y elementos; ¿Cuándo se hacen?, muestra su estilo señorial o de castillo-palacio mudéjar propio del siglo $\mathrm{XV}$, con el uso de barreras artilladas perfectamente adaptadas a los estragos; ¿Cómo se hicieron los castillos?, señala que se debían hacer con permiso real, dependiendo de los materiales de la zona, y con presupuesto de reparación procedente de impuestos especiales aplicados en las villas o aldeas dependientes; Emplazamiento de los Castillos, nos indica la gran variedad de lugares elegidos para su construcción, desde peñas inaccesibles a vaguadas para esconderse de la artillería; asimismo, la relación con las villas o ciudades era muy variada; Los constructores de un castillo, indica que eran los canteros o maestros de cantería los que se atribuían normalmente la traza y la ejecución material de la obra; finalmente, El Castillo y Alcázar de 


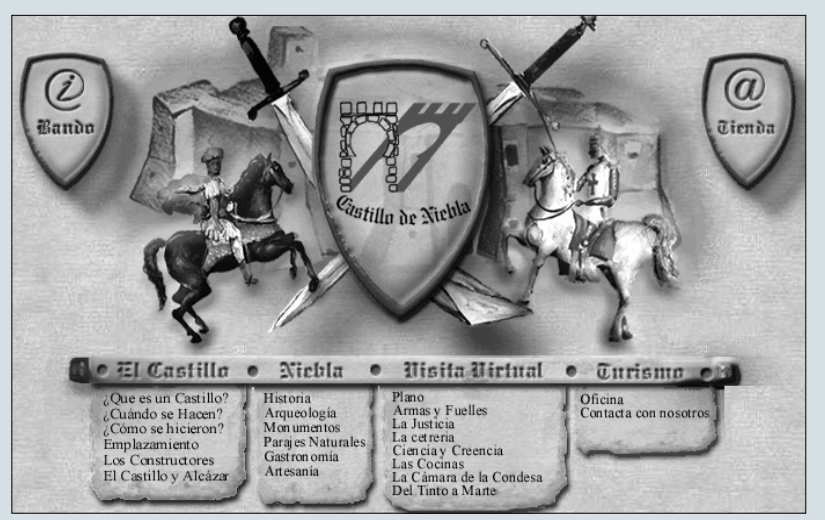

Niebla, resalta el carácter de palacio-fortaleza del edificio, objeto de numerosas remodelaciones, reparado tras la conquista y fruto de daños y saqueos a lo largo de la historia.

\section{Visita Virtual}

A través de esta entrada accedemos a una información que nos muestra los aspectos históricos y antropológicos de la época reflejados a lo largo de los siguientes apartados:

Plano del castillo, donde se aprecia la estructura de las diferentes plantas del castillo, además de su situación geográfica con respecto a la ciudad; Armas y Fuelles, muestra las piezas de artillería más utilizadas en la época, así como el uso de la pólvora como elemento novedoso en los avatares bélicos; La justicia señorial, donde el señor ejercía la plenitud de sus derechos jurisdiccionales rigiéndose la población por las reglas de Castilla; La cetrería medieval, nos habla de la tradición de la caza por aquella zona, así como de la fama que en la época adquirieron los halcones; Ciencia y creencia de la Edad Media, hace hincapié en la influencia árabe en el mundo de la ciencia y de los avances en matemáticas, astronomía, medicina, farmacia, botánica y agronomía; Las cocinas del Alcázar, muestra la diferencia que existía entre los pobres y los ricos en cuestiones gastronómicas, y habla del pan, la carne, el vino y el pescado como base alimenticia del condado, además de otras peculiaridades culinarias como los alfajores y pestiños, gachas de carne y sémola, empanadas de guisantes o albóndigas con comino; La cámara de la condesa, nos muestra datos sobre la vida familiar de la nobleza, con familias de muchos hijos aunque con una alta mortandad infantil. También muestra aspectos del papel social de la mujer, del mobilario y de la autosuficiencia del castillo en cuanto a la existencia de talleres y al abastecimiento de todo tipo de productos; finalmente, tenemos un peculiar apartado destinado a comparar los elementos minerales que dan color a las aguas del río Tinto con algunos de características similares encontrados en la superficie del planeta Marte.

\section{Niebla}

Este apartado actúa dentro de la página web como elemento de conexión entre el castillo y su entorno a través de los siguientes apartados:

Niebla, tres mil años de historia, hace un breve recorrido sobre las distintas etapas históricas, desde la protohistoria hasta la época antigua y la conquista cristiana; Arqueología, nos habla de la evolución de la trama urbana de la ciudad de Niebla, resultado de una superposición de restos arquitectónicos debido a la antigüedad de los asentamientos del terreno; Conjunto histórico-monumental, es un apartado de sumo interés que realiza un recorrido por todos los recintos y monumentos emblemáticos de la ciudad, desde las iglesias más relevantes hasta el Alcázar de los Guzmán, pasando por un análisis de las sucesivas murallas de la ciudad; Parajes Naturales, indica la existencia de maravillosos espacios naturales para disfrutar de la Naturaleza del entorno, tales como pantanos, parajes y albergues; Gastronomía, muestra las tradiciones gastronómicas antiguas, así como una lista de platos actuales y de restaurantes para degustarlos; Artesanía, analiza la importante tradición artesanal de la ciudad tales como las canteras, el trabajo de la piedra, el trabajo de los guijarros, la alfarería y la cerámica, la zapatería, guarnicionería, la empleita (trabajo de palma típico), los bordados; etc.

\section{Turismo}

Finalmente, en esta última entrada, cabe destacar el apartado dedicado a La oficina de Turismo, sita en las dependencias del castillo y encargada de la realización y puesta en valor del mismo; la Tienda on-line, con productos promocionales, decorativos y de recuerdo, que nos muestra una selección de artículos seleccionables con la posibilidad de formalizar el pago contrareembolso; y un apartado destinado a Contactar para realizar a través de un formulario consultas o sugerencias, así como un Bando que muestra la agenda de actividades culturales que todos los veranos se realizan en el castillo, tales como espectáculos de teatro y danza y veladas andalusíes durante los meses de Julio y Agosto, todo ello para contribuir a su promoción y conocimiento.

En definitiva, se trata de un recorrido muy completo que centra al visitante dentro de una época y una sociedad con sus costumbres y normas, al tiempo que da a conocer su entorno histórico, natural, gastronómico y artesanal más cercano.

La navegación es sencilla y siempre permanece el índice inicial como punto de referencia en el lado izquierdo de cada página. Del mismo modo destaca la presencia de todos los apartados existentes, en la parte inferior de las mismas. La información que presenta está muy bien seleccionada y, aunque las fotografías que acompañan al texto no se amplían, sirven de útil referencia ilustrativa a la lectura de los textos.

En conclusión, estamos ante una sede web que dada su vocación de atraer al visitante hacia este entorno histórico aún vivo, ha dedicado sus páginas a la muy útil divulgación de todos los aspectos que pueden llegar a encerrar los muros de estos edificios que por su aspecto misterioso e inaccesible, siguen siendo los grandes desconocidos de la historia.

\begin{tabular}{ll}
\hline FICHA DE LA WEB & \\
\hline URL PRINCIPAL & http://www.castillodeniebla.com \\
\hline TITULAR & PROMAVI, S.L. \\
\hline INFORMACIÓN & Muy Buena (variada y útili) \\
DISPONIBLE & \\
\hline CALIDAD GRÁFICA & Regular \\
\hline DISEÑO WEB & Óptimo \\
\hline FACILIDAD DE NAVEGACIÓN & Muy Buena \\
\hline VELOCIDAD DE CARGA & Rápida \\
\hline ACTUALIZACIÓN & $\begin{array}{l}\text { Buena (contempla una sección } \\
\text { fija y otra actualizada con } \\
\text { eventos para el verano de 2001) }\end{array}$ \\
\hline CALIDAD GLOBAL & Buena \\
\hline
\end{tabular}

Susana Limón Rodríguez Centro de Documentación del IAPH 